\title{
Theory at all Points: A Methodological Quest for Psychotherapy Research
}

\author{
Florian Dreyer ${ }^{1}$ \\ International Psychoanalytic University (IPU)
}

\begin{abstract}
There is the common believe that data and theory are two distinct poles on the same scientific continuum. This notion is enriched with ideas from the fields of psychoanalysis, sociology and conversation analysis. The description of conversational reality in accordance with the knowledge of psychotherapeutic theory is exemplified through the analysis of a therapy transcript. A special spotlight is shed on the dyads' use of the recipient signal "mhmh" and its various functions within the talk. Most prominently, the therapist uses this token to reinforce the patient as long as she follows his idea of how she might get better. This small insertion therefore functions as a conversational marker of handling a therapeutic theory. Conversation analysts think of talk as a subject not predetermined by theoretical believes of the participants. This changes in the analysis of therapeutic talk, which is pre-structured, at least by the professional theories of the therapist. For a proper analysis of the conversation two systems should be taken into account. On the one hand Harvey Sacks' idea of 'Order at all points' and on the other hand the methodological idea of 'Theory at all points'. This combination leads to a description of conversational reality while taking theories into account.
\end{abstract}

\section{Introduction}

There is a reason why most of the performances of the first two symphonies by Johannes Brahms are way shorter than the composer himself intended them to be. In both of them, Brahms included a repetition in the first movement that is often left out in concerts. Why? Because you already heard it. Some listeners think: "Oh, I've heard this before, why do I have to hear it a second time?" Some might even get angry. During my work in the CEMPP-project (Conversation Analysis of Empathy in Psychotherapy Process Research) I transcribed three sessions of cognitive behavioural therapy in a fine-grained manner. Little by little I got more and more upset with the transcription. This shouldn't come as a surprise because transcription isn't a researchers' dream but rather fulfilling a duty. But I was more than mildly irritated during my work, which made me wonder: "What is it in this psychotherapy recording I cannot stand?" Some days later, in one of our weekly research group meetings with Marie-Luise Alder, Michael Dittmann and Prof. Michael Buchholz, it struck me. There was a constant repetition of the recipient signal "mhmh" carried out by both patient and therapist. The amount of these repetitions exceeded everything we've heard before. This text deals with the question what the two participants are doing with their "mhmh" and draws conclusions for the analysis of

${ }^{1}$ Correspondence concerning this article should be addressed to Florian Dreyer, International Psychoanalytic University (IPU), Stromstr. 2-3. 10555 Berlin, Germany. E-mail: florian.dreyer@ipu-berlin.de.

Language and Psychoanalysis, 2016, 5 (2), 27-45

http://dx.doi.org/10.7565/landp.v5i2.1559 
therapy transcripts. By the way even Brahms stopped the repetitions in his later works. The score of his last symphony doesn't contain one single repeat mark.

\section{From Musical to Scientific ideas}

In the year 1982 the famous sociologist Jeffrey Alexander wrote the widely cited quote, that "science can be viewed as an intellectual process that occurs within the context of two distinctive environments, the empirical observational world and the non-empirical metaphysical one" (p. 2). With this sentence, Alexander elegantly avoids the notion of a contradiction between the empirical and the metaphysical point of view. He subsumes both under the idea of an "epistemological continuum" with said points of view as polarities. He arranges it in a one-dimensional figure (see Figure 1) of a line on which, in his words, "one can [...] arrange all the different components of scientific thought in terms of such degrees of generality and specificity."

THE CONTINUUM OF SCIENTIFIC THOUGHT

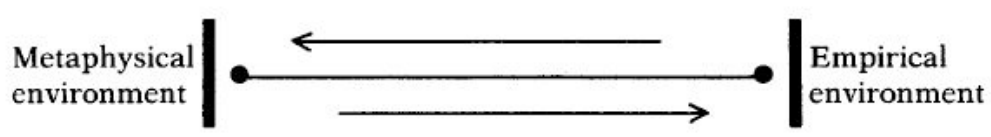

\section{Figure 1}

The continuum of scientific thought

Scientists are therefore moving leftwards and rightwards and claim to have a position on this continuum while doing research. This idea of different positions on the continuum is elaborated by Alexander, after he introduces this first model.

\section{Data and Theory}

While explicating the idea of the continuum, he introduces the concepts of data and theory. He does this through the division of the continuum in smaller parts. The dividing points are labelled as in Figure 2. 
THE SCIENTIFIC CONTINUUM AND ITS COMPONENTS

Metaphysical

environment

Empirical

erıvironment

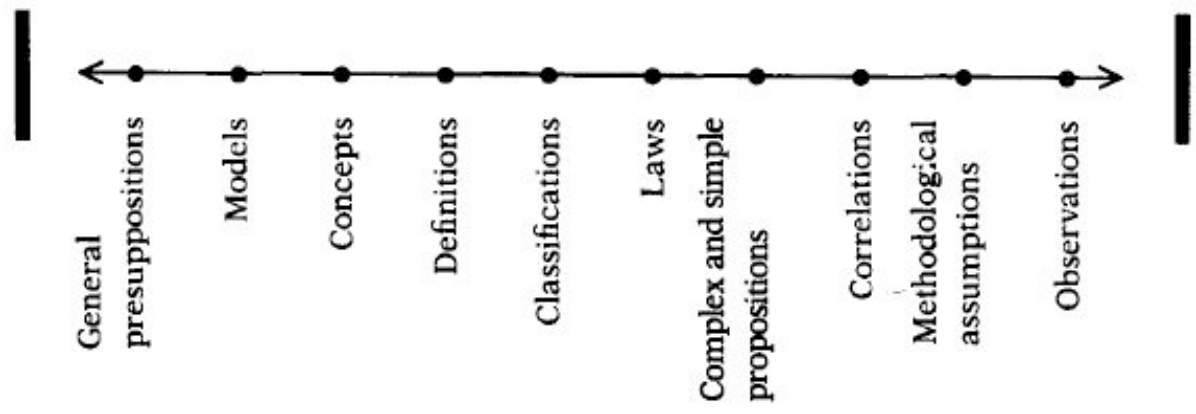

\section{Figure 2}

The scientific continuum and its components

With these dividing points, every scientific thought can be placed alongside this measurement, enabling an adaptable point of view, concerning the question of what is data and what is theory. For Alexander, everything to the left of a given point of view is called theory, while everything to the right would be data. For example, a psychiatrist using a chapter of an internationally distributed classification system as the International Statistical Classification of Diseases and Related Health Problems - ICD (Dilling, Mombour, \& Schmidt, 2008), may see correlations between different mental illnesses as data, while using a model of psychopathology as a theory, in which he or she integrates the classification system. Data and theory are therefore constantly intermingled.

\section{From Freud to Blumer}

An aspect that should be brought into consideration is Freud's idea of a linking between healing and research. For him, there is no gaining of insight without a curative effect on the patient, neither is there a cure that doesn't contain fruitful findings which may be implemented in theories (Freud, 1926e). With this idea, Freud manages to interweave data and theory. They are no longer separated in "what theory says" and "what therapy says", but rather placed on a continuum as Alexander proposed it.

Whether one would share Freud's following thoughts or not, that psychoanalysis is the only method using this concept, one idea rises from this starting point. An idea, coproduced by the patient and the therapist in order to explore and/or cure the problems displayed in the session, also acts as starting point for the building of personal theories of both therapist and patient. This notion resembles a concept brought into being by Herbert Blumer. Blumer $(1954$, p. 7$)$ proposes to look at theories as "sensitizing concepts." He explains: "[...] it [the sensitizing concept] gives the user a general sense of reference and guidance in approaching empirical instances. Whereas definitive concepts provide prescriptions of what to see, sensitizing concepts merely suggest directions along which to look."

Language and Psychoanalysis, 2016, 5 (2), 27-45

http://dx.doi.org/10.7565/landp.v5i2.1559 
This mechanism also works the other way round. Personal or explanatory theories, brought into the session by either therapist or patient, on which they both agree, may enhance the curative power of the shared talk. A shared theory results in an increase of the common ground of the speakers, in a "general sense of reference and guidance".

\section{Harvey Sacks - Order at all Points}

To put this idea in a more abstract form, there is a constant exchange between the immediate talk of patient and therapist and the various personal, explanatory, ordinary and professional theories running through their minds. One could say, that theoretical ideas and the empirically observable talk of the participants take place at the same time. Although those theories are not directly observable and the idea is not to ascribe an intentional, theory-based usage of utterances to the participants of the talk, a negation of the presence of theory in the talk would bereave the analysis of therapeutic conversation of one of the core therapeutic elements. From this consideration arises a serious problem: When theory plays a major role in therapeutic talk, how can we know which one is currently in the minds of therapist and maybe patient. The short answer is: We can't. For the long answer, a sidestep is needed to Sacks' (1995) Lectures on Conversation. Sacks starts with an observation:

Now, for whatever reasons there were, the social sciences tended to grow such that the important theories tended to have a view that if you look at a society as a piece of machinery, then what you want to consider is the following: There are relatively few orderly products of it. There is, then, a big concern for finding 'good problems;' that is, to find that data which is generated which is orderly, and then attempt to construct the machinery necessary to give you those results (p. 483)

For Sacks there was a main concern in social sciences research. Professionals reverse the standard way of research. Starting from the 'chaotic' society there is a need for an orderly question from which an equally ordered research design may evolve. Said question is determined by various kinds of interests. For example the theoretical beliefs of the researcher, interest in publishing texts fitting into the focus of research journals or the need to satisfy the financier of the whole study. Such a pre-structured design leads to the acquisition of pre-structured data, which is later used to confirm the formerly established theory.

Behind such a way of thinking is the assumption that the "thing" a theory should describe, exists. In view of the fact that a theory should prove stable over time, the "thing" itself has to show this stability too.

Sacks proposes a methodological idea on how to take said pre-structured designs into account. He postulates that the idea of replicable, constant research findings is a misconception based on the fact that 'order' is imposed by the researcher himself. If one 
wants to find order, one will find order. He explicates this by depicting how statistical procedures come along with vast amounts of constraints and an in-built uncertainty, but nevertheless succeed in ordering the (psychological) world. Here the question becomes obvious, whether the statistical procedure produces, discovers or imposes order.

There is no way around the creation of a specific order in research which, by itself, is no problem at all. It becomes difficult in the moment the researcher stops taking into account that this order is, at least partly, imposed by himself. Sacks' idea of order at all points tackles this difficulty on a more basic level. For him there is "Order at all points" (p. 484) which means that, in social sciences, one has no need to build research designs, or as he put it: large machineries, enabling a researcher to observe a recurring, stable and reproducible pattern. Rather one may observe and describe carefully what is going on around oneself.

\section{The Methodological Proximity of Conversation Analysis and Psychoanalysis}

When researching psychotherapy there are also conversational actions at work, which order the therapeutic talk. In most psychodynamic approaches, the therapy is carried out and perceived as a "talking cure". This term was coined by Berta Pappenheim, a patient of Josef Breuer. Freud (1910a) describes her case as follows:

The improvement in her condition, which would last for several hours, would be succeeded next day by a further attack of 'absence' and this in turn would be removed in the same way by getting her to put into words her freshly constructed phantasies. [...] The patient herself, who, strange to say, could at this time only speak and understand English, christened this novel kind of treatment the 'talking cure (p. 11)

Although the metaphor of 'putting something into words' may be criticised in terms of conveying a hidden meaning behind the words, which is done brilliantly by Leudar and Costall (2009b) referring to Reddy (1979), this shall not be the point of interest. Freud himself transforms the notion 'put into words' to 'speak and understand' and manages to bring in the communicative partner. The 'talking cure' itself is being grounded in the conversation of Pappenheim and Breuer or, more general, in the communication of the two participants. This idea remained over the last century. Irrespective of the therapeutic school, communication is seen as an interaction between the therapist and the patient (for psychodynamic therapy (PT) see Streeck (2006) and for cognitive behavioural therapy (CBT) see Hoyer, Jacobi, and Leibing (2006)). Following from this, therapy may be described and observed through the methodological glasses of conversational order at all points. CBT as well as PT use communication as a means to place methods in the therapy. 'Interventions' come with the same regulations, as the therapist is placing an utterance to stop the patient from continuing a behaviour, topic, etc.. The term derives from the Latin word 'intervenio', which literally translates to 'coming in between'. But in between what? As the talk of the patient is interrupted, the therapist places his or her 
utterance between what has been said previously and what is anticipated by the therapist to be the continuation of the prior talk. An assumption of what will be said is deemed to be trustworthy enough to change the trajectory of the talk. Arriving at this point, a knowledge gap opens up: How does the therapist know what the patient is going to say? The methodological problem of this question is dealt with in Leudar and Costall (2009a); here we can state that the term of 'intervention' always involves some sort of intentionality, a theorizing about the other.

\section{Ascription of Intentionality versus Description of Conversational Reality}

This assumption of an intentionality resembles the previously mentioned idea of Sacks. 'Interventionists' apply a 'machinery of methods' which produces, discovers or imposes order in the thoughts and feelings of the patient. An utterance of the patient leads to an intervention of the therapist with which he or she tries to adjust the assumed pathological continuation of the other. In CBT this adjustment is achieved mostly through learning procedures. PT on the other hand uses the information perceived in the talk alongside the feelings and ideas of the therapist. Both therapies transcend the pure observation and description of what is seen in the session so as to discover order. An order seemingly necessary to help the patient. Remembering the idea of Sacks one may ask the question, whether said order is truly discovered, (co-)produced by the two participants or even imposed by the therapist. Following Leudar and Costall the difficulty of ascribing intentionality and therefore theorizing about the other may be avoided by extended observation and description of the conversational reality. Rather than 'Why is X doing Y?' one may ask 'How is $\mathrm{X}$ doing Y?' Applying this methodological idea of Conversation Analysis to psychotherapy, as well as psychotherapy research, the same shift occurs. Instead of 'Why does $\mathrm{X}$ behave in a way Y?' or 'Why does $\mathrm{X}$ feel Y?' both participants would observe and describe 'How is X expressing his/her behaviour/feeling Y?' There are loads of fruitful findings once one applies this structure of questioning the material.

\section{Interplay of (Psychotherapeutic) Theory and Conversation Analysis}

Taking a closer look at the program of the ICCAP 2016 (International Conference on Conversation Analysis and Psychotherapy) it becomes clear, that concepts like "collaboration", "empathy", "resistance" and "interpretation" have found their way into the analysis of conversation. This observation itself is not problematic. It becomes difficult with the idea that constructs, with a history, deeply embedded in a theoretical frame, may be explored and even explained solely through an atheoretical method. The usage of the terms themselves comes with the imposition of a range of theoretical thoughts. If these are left aside in the analysis, the concept itself is weakened to a point where it is nothing more than a pseudo-defining shell conveying an unclear subset of features.

This leads me to the idea of "Theory at all points" (TaaP). The combination of "at all points" is taken from the previously mentioned Lectures on conversation. It emphasizes the uncertainty whether a researcher is discovering or imposing a theory in the data. As

Language and Psychoanalysis, 2016, 5 (2), 27-45 
well as order, theory itself is not only not problematic but a "sensitizing concept" along which to look. Stretching the idea by Sacks even further, if one engages in the search for an indication of a specific theory of one of the participants, one will find it. It's not a new finding that there is a confirmation bias in science. Therefore my proposition is to take into account that the apparently discovered indications for theories (of the participants) may as well be produced or imposed by the researcher. The same holds true for clinicians talking to their patients. To order their own perceptions of what is going on in the therapeutic talk, therapists build up their own local sensitizing concepts, their own theories. At this point it should be noted, that the term 'theory' itself stems from the ancient Greek word "theōria" which literally translates to "looking at" or "gazing at". Perception is therefore an in-built feature of theory. To put it in therapeutic terms: The perception of what a patient is saying comes along with the building of a local, ad-hoctheory of the therapist. Those ad-hoc-theories are, to a large extent, influenced by the meta-theoretical schools of thought the therapist commits himself to.

To take into account that psychotherapy sessions are a form of communication that is asymmetric insofar that the therapist has a theoretical, as well as a practical training functioning as a supplementary tool in the talk, possible concepts of a meta-theoretical school of thought should also have their places in the analysis of the talk. Those concepts have to be describable within the transcript to meet the idea of "How is X doing Y". Through this, there once again occurs a shift from the question "Why does therapist $X$ react in a way $Y$ to patient $Z$ ?" to the question "How does therapist $X$ react to patient $Z$ ?" The way the therapist is reacting is no longer only seen as an outcome of an application of a meta-theoretical frame of mind to another person's mind but rather as a communicative event co-constructed by two persons.

\section{Analysis of a Transcribed Psychotherapeutic Session}

This idea will be explained with the help of a transcribed psychotherapy session. This session is part of our CEMPP-project (Conversation Analysis of Empathy in Psychotherapy Process Research) located at the International Psychoanalytic University (IPU) in Berlin. Under the guidance of Prof. Michael Buchholz and Prof. Horst Kächele, a group of students transcribed 45 therapy sessions on GAT-level (Selting et al., 2009). The sessions were taken from the corpora of the "Münchner Psychotherapiestudie" (MPS) (Huber, Klug \& von Rad, 1997). All of the transcribed patients were diagnosed with depression. The patient conveys to the therapist that she will be busy with her final exams for the next months and therefore may not be able to focus on one of the main therapeutic goals, "getting in touch" with herself. She tells the therapist that those final exams act as obstacles, blocking her way to the establishment of a self-contact. In this surrounding, the following scene occurs.

\section{The Transcript}

1 T: dass Sie da: hh (---) äh:: kein Kopf dafür haben, werden, für Privates, $(1,5)$

2 that you there (---) won't have a head for, for private stuff $(1,5)$ 
$3 \quad{ }^{\circ}$ also; ${ }^{\circ}$

4 well

$6 \quad$ P: also ich denk halt bis der zwei(h)te $\mathrm{Ma}(\mathrm{h}) \mathrm{i}$ vorbei ist;

$7 \quad$ Well I think until the 2nd of May has passed

8 T: $\quad$ bis der zweite Mai vorbei ist; $<$ und dann $>$ denken Sie $<$ sieht's

$9 \quad$ Until the 2nd of may has passed and then you think it'll look

10 wieder $\mathrm{n}$ bisschen anders [aus;

11 a little bit different again

12 P:

13

Yes I do think so

$\left[{ }^{\circ} \mathrm{ja}\right]($.$) denk ich schon { }^{\circ}$

$14 \quad \mathrm{~T}: \mathrm{mh}[\mathrm{mh}::$, $]$

15 P: $\quad\left[{ }^{\circ}\right.$ und $\left.\mathrm{da}^{\circ}\right]$ is nur noch eine Sache auf die ich mich dann $\mathrm{zu}$

16 And there is only one thing on which I have to

17 konzentrieren hab [und]

18 concentrate and

19 T:

$20 \quad(1,0)$

21 P: $\quad$ also abgesehen jetzt von der Stellensuche a:ber;

22 well despite the search for a job but

$23 \quad \mathrm{~T}: \quad \mathrm{m}:: ;=$

24 P: $\quad={ }^{\circ} \operatorname{des}^{\circ}(2,0){ }^{\circ}$ denk ich wird auch noch, ${ }^{\circ}$

25

this $(2,0)$ i think will work out too

26 T: $\quad$ hm:: mhmh:, $(1,5)$.hhh na ja. $(-)$ ähm: $(1,3)$ also Sie kommen ja

27

hm mhmh (1,5) well (-) ähm $(1,3)$ so you do get

28

zurecht [jedenfalls]

29

along anyway

$30 \quad P$ :

[mhmh,]

In the following description of the transcript, I will use the numerations of the lines in the German original. The corresponding English translation is located right under the German version. 


\section{Description of the Conversation}

The therapist starts in line 1 by emphazising that the reason why the patient is momentarily not able to get into contact with herself is because she "won't have a head for, for private stuff". This is followed by a pause of 1.5 seconds and the subsequent "well", which are used for passing the conversational floor. It takes another 2.7 seconds until the patient responds to this ascription with a temporal restriction of what was formerly said. The particle "halt" (line 6) weakens the previous account, in this example the description of her own thoughts. This weakening is restricted to a period of time until the $2^{\text {nd }}$ of May. The therapist rephrases the last part of what the patient has said and completes the assumed rest of her sentence. With the alleged finish of her sentence the therapist emphasizes the meaning of an end of this temporal restriction. "<und dann $>$ denken Sie <sieht's wieder n bisschen anders aus;" (lines 8 and 10). This completion by the therapist implicates that it had already looked a little bit different before. Therefore he speaks about returning into a previous state, a state that the patient has left only temporally. This utterance can be linked to his first sentence. The patient can start once again to have a head for private stuff. The return into this previous state is facilitated through the notion "n bisschen". Said notion takes away the immediacy and weight inherent in such a return. Through this small addition, returning can be seen as a gradual process.

The patient answers, in a quiet voice, that she believes in a return on the $2^{\text {nd }}$ of May but the word denken (to think) allows for the possibility that she might not have a head even after the negotiated date. She does not know whether something will change then, she only thinks it.

The therapist answers to this partial agreement with the short interjection "mhmh::,". He signalizes through the usage of this small particle that he received the agreement of the patient. Subsequently, she herself does not wait until the therapist finishes his interjection but starts to add further information to what she previously said ("ja denk ich schon" line 12). She starts with "und da" (line 15), depicting that everything following from this point is also attributed to the time after the $2^{\text {nd }}$ of May. From this day on, she would only have one more thing to concentrate on (lines 15 and 17). What this "one more thing" might be is not directly clarified. Right before this depicted scene, the two are talking about whether the patient wants to get more into contact with herself. That's why it is likely that the one more thing to concentrate on is she herself, respectively her private life. With this thought the task to get into contact with oneself would turn into a challenge for her abillity to concentrate.

This extension of the patient is answered by the therapist with a recipient signal (line 19). Following Ehlich (1979) I subsume all possible combinations of [m], [n] and [Ә] (which additionally can be linked by a $[\mathrm{h}]$ ) under the term recipient signal. This time, the therapist uses a two-part signal, in which the second part is mentioned at exactly the same moment the patient places her "und" (line 17). This "und" shows that she hasn't finished her sentence yet. At least a subclause would have been added here. The first part of the two-part interjection coincides with this signal of an extension of her sentence. She stops said extension and the therapist commences with the second part of his interjection, the "mhmh:,". Afterwards another pause is formed, this time with the length of 1.0 seconds (line 20) after which the patient restricts the previously said once again. 
To her opinion she has to deal not only with getting into contact with herself, but also with the search for a workplace (line 21). Once again she will not be able to fully concentrate on her quest for getting into contact. To put it in a different phrasing: From May on, there will only be one thing I'm gonna focus on, except the other thing that is important then. This new limitation implemented by the patient is answered by the therapist with a recipient signal once again. While the first two interjections (lines 14 and 19) expressed an agreement (this is achieved through the fact that these interjections have a two-syllable structure with a rising intonation contour in the end) towards what has been said by the patient, the recipient signal in line 23 only has one syllable. Here (line 23 ) the therapist doesn't show agreement anymore but rather reacts with an information receipt token (O'Keefe \& Adolphs, 2008). The patient, as a reaction to that, restricts her own previously made limitation after a pause of 2.0 seconds (line 24 ).

She again uses the impression "denk ich" (I think, line 24) and describes that the second thing, the search for a job, will work out too. At this point she does not speak about her own contribution to this "working out". She expects it to settle by itself. Afterwards, the therapist continues with a combination of two recipient signals, first a one-syllable-token which is prolongued and second a two-syllable-token. Initially he again starts with an information receipt token which is subsequently accompanied by the two-syllable-token "mhmh:," showing agreement with what the patient has said. Following a pause of 1.5 seconds, the therapist starts with a "Na ja" (well) (line 26). The various perspectives on this small particle were described by Harden (1989). He divides the particles on the basis of their phonological form. The way the "Na ja" is pronounced in this sequence, the point in the end is an indicator for a falling intonation in the end of the " $\mathrm{ja}$ " is pictured as followed (p. 143):

The na ja of this type can be constantly interpreted as a deliberative utterance concerning a previous utterance, which shall neither be totally confirmed nor totally denied. In other words, the speaker signalizes that the previous utterance is only to some extent suitable to the complexity of the topic. (Author's own translation from Germany to English)

If one follows the perspective of the author on the particle, there are two possible versions how the shown example of "Na ja" can be understood.

a) The therapist ponders over the patient's last utterance. He neither confirms, nor denies her last sentence in line $24 .\left({ }^{\circ} \mathrm{des}^{\circ}(2,0){ }^{\circ} \mathrm{denk}\right.$ ich wird auch noch, $\left.{ }^{\circ}\right)$

b) The therapist ponders over his own previous utterance. The Confirmation ("mhmh:," in line 26) of what the patient has said becomes the object of a subsequent confirmation or denial. The importance of the "mhmh:," is reduced.

After a short pause of around 0.3 seconds, the therapist delays the ongoing talk even further. He achieves this through an "ähm" (line 26) right before the next pause of 1.3 seconds. After this assembly of hesitation markers he begins a new sentence in which he 
starts a summary of what has been previously said. This is made clear through the use of the particle "also" (so) and the adverb "jedenfalls" (anyway). Both words are linked to a prior communicative element. Throughout the whole sequence there are differently articulated interjections of the therapist. The importance of those small bits of speech shall therefore be further examined.

\section{An Interjection about Interjections}

The term "interjections" describes a collecting basin for completely diverse words and utterances. In earlier works on this topic there often occurs the question of why such ubiquitous particles of speech have been researched so poorly. Schachter and Shopen (1985) describe this fact under the circumstance that each and every language owns its own subset of interjections. Possibly one might get to an answer through the reception of Schegloff (1982). He delineates that the widely used division into "real talk" and seemingly conversationally irrelevant "detritus" (p. 74) has a meaning. Schegloff impeaches the characterisation of relevant and irrelevant talk and therefore tries to widen the focus of attention towards those apparently irrelevant features of conversation. This "detritus" enables the participants of a talk to see their shared communication as a product of two different minds. The ongoing small signals coming from a listener help the speaker to see him- or herself inter-acting with somebody else. The partitioning of speech into "relevant" and "irrelevant" would be a necessary presupposition for the detection of locally distributed roles in the talk, namely speaker and listener. Moving a step further: By starting to treat the "detritus" as conversationally relevant as well, consequently following Schegloff, the (necessary) illusion of separated roles in talking and therefore the illusion of separated speakers would collapse. Communication would emerge as a model where the participants share a medium through which understanding is achieved. This idea leads in the same directions as for example the "dyadic state of consciousness" (Tronick, 2005) or the "bidirectional interactive field" (Aragno, 2008).

\section{Categorization of Interjections}

Probably the widest known categorization is the division into primary and secondary interjections. While secondary interjections are either parts of words or a combination of such parts imbued with definite meaning, primary interjections are "phonologically and morphologically anomalous" (Ameka, 1992a, p. 105). Primary interjections are built out of sequences of sounds that may not be found in other parts of the language. Norrick (2009) is working with the pragmatic (in the linguistic meaning) effects of primary and secondary interjections on the turn-taking structure of talk. Norrick underlines the special importance of the intonation contour when observing interjections. This seems logical concerning the unclear semantic structure of most of the interjections.

Rodero (2011, p. 25) adds the following: “...it is understood that the emotional load conveyed by intonation is sustained by movements in the intonation curve and by pitch levels".

Primary and secondary interjections share the feature that they appear separated from other utterances in a way Bakhtin (2010) describes it. He postulated that there has to be a short pause of speech between two utterances, to detect that they are not connected to one 
another. Therefore they can't be directly connected to other utterances as a pre- or suffix to them. Neither can they be woven into an utterance without distinct pauses indicating the limits of the interjections. A good overview can be found in a text by Ameka (1992a). $\mathrm{He}$ starts with the features of interjections that were brought together by the ancient Romans. Interjections include "non-words" (p. 102) what might be a hint for the nonlexical origin of some interjections. They derived from nature sounds rather than being developed out of a language. Furthermore, the interjection is neither affected by the surrounding syntactic form nor has it a grammatical function. Ameka concludes that interjections develop as a "reaction to a linguistic or extra-linguistic context, and can only be interpreted relative to the context in which they are produced" (p. 108).

Ameka also emphasizes that even in the ancient world interjections were seen as means to convey a feeling or emotional state. This still holds true in the modern days. An example for this property can be seen in Goffman's (1978) "response cries". Ameka implements a division into expressive, conative and phatic interjections. As an example, the expressive ones show how the speaker feels in the present moment. Examples for this type are "Ouch" or "Yuck". The conative and phatic interjections are dealt with in another work by Ameka (1992b). To sum it up: Conative Interjections focus on the gaining of attention while phatic ones are partly responsible for structuring and maintaining the talk itself. They are auxiliary particles which do not have to have lexical meaning themselves but are nevertheless highly important for the continuation and the order of the talk. The group of the recipient signals are phatic interjections as well.

\section{Recipient Signals in the Text}

The first appearance of such a recipient signal in the shown transcript is in line 14. In advance the patient describes the date up to which she won't "have a head" for her "private stuff". The problem with this is that "private stuff" is highly relevant for the therapy. The therapist takes her statement into account and rephrases it. He also adds a new perspective to the talk; namely a possible change of pace after the $2^{\text {nd }}$ of May. Although the therapist did not raise his voice in the end of line 10, it is clear that he is asking her a question. This becomes evident when the patient answers him in line 12 . This answer also ratifies the perspective the therapist opened up before. His idea of a possible change from the $2^{\text {nd }}$ of May is agreed upon by the patient. As a reaction to this agreement the therapist offers a two-syllable-token "mhmh::," in line 14 with an rising intonation in the end. This phonological form is attributed to agreement by Ehlich (1979). The agreement is even strengthened through a prolongation of the second syllable. This syllable is around 0.5 seconds longer than expected.

Directly afterwards the patient continues to think about the perspective brought into being by the therapist (line 15). She even underlines that, after the $2^{\text {nd }}$ of May, she has the potential to concentrate on only one thing, getting in contact with herself. The therapist starts, as the patient is still speaking, with the continuation of giving recipient signals. He accompanies her at first with a prolonged "m:::" with falling intonation towards the end. According to O'Keefe and Adolphs (2008, p. 88) this particle shall be understood as information receipt token. This group of particles are "strongly associated with asymmetrical interaction where one of the participants is a power role holder". After this token, he goes on with another prolonged two-syllable-token, depicting confirmation. The 
two tokens in line 14 and 19 are nearly similar concerning their prosodic features. But not only the way they sound resemble one another, also is their conversational surrounding quite alike. Both times it functions as a confirmation of what the patient has said. And both times the patient previously did follow the perspective brought in the talk by the therapist in lines 8 and 10 . He confirms that she is still "on track".

The next instance of a recipient signal occurs in line 23 . After a pause of 1.0 seconds, the patient restricts her own, previously made utterance. She opens up to the therapist that, next to her "private stuff", she also will have to deal with her search for a job (line 21) and is rewarded with another information receipt token, prolonged as well and also with falling intonation. But this time there is no second, confirming, two-syllable-token. Therefore the information receipt token, which is associated with an hierarchical asymmetry in the talk is standing all by itself. The therapist does not give any sign of confirmation to the patient. She continues without a pause in line 24 but does not end her sentence immediately. It takes another pause of 2.0 seconds until the patient is ready to say that the search for a job will work out too. In line 21 she displays her second thoughts about the possibility of a change from the $2^{\text {nd }}$ of May on. Those doubts are dispelled by herself directly after the information receipt token by the therapist that is not accompanied by a two-syllable-confirmation ("mhmh,"). After she stepped back from her further concerns the therapist reacts again with two recipient signals, this time to her notion of stepping back. The first on, in line 26, cannot be interpreted clearly due to the unchanging intonation. The second one is, once again, a two-syllable confirmation. The therapist brings this signal of confirmation in exactly the moment where the patient starts or restarts to approximate his perspective. He always confirms when the patient moves towards his own points of view and shows an information receipt token the only time she dares to disagree with his thoughts on how she should get in contact with herself. This Go or No-Go idea gives the observer a feeling of looking at a mechanised communication. Only when the patient does the appropriate thing, namely developing the idea of the therapist, a reward by the therapist can be achieved.

\section{Widening the Scope of Analysis}

So far for the description of this short episode of a therapy session. This first part of the analysis was strictly focusing on the structure of the talk. A fine-grained report of what is happening in the interaction of the two participants comes close to the original concept of "theōria". As mentioned before it literally translates to "looking at" or "gazing at". Over the last pages we took a look at the communication with a far higher resolution than everyday-talk is allowing it. This close look enables possible readers to follow the author's thoughts as well as enabling the reader to profoundly disagree. In the case of an improper interpretation by the author, the reader has the possibility to discriminate whether the problem is in the description of the transcript itself or occurs later in the more theoretically founded parts of the analysis.

As researchers we are dealing with parts of therapies, probably years after they were recorded. This brings us into the privileged position of having as much time as we want. In contrast to the clinicians, we don't have to react immediately to an utterance another person made. Analysing a conserved communicative event places the researcher in a reconstructing position. The reconstruction itself is fed by the observation of a past event. 
In addition to mere observation however, there is further information concerning the context of the talk. The context in which the talk took place plays a major role in the subsequent analysis. For the example worked on, it is known that the therapist underwent training in cognitive behavioural therapy. The sequence stems from a recording of a $16^{\text {th }}$ session of the therapy making it one of the middle sessions. Furthermore we know that the patient is diagnosed with depression. There is no further information concerning the severity of the illness and eventual comorbidities.

\section{Cognitive Behavioural Theories about Depression}

Cognitive Behavioural Therapy (CBT) has the idea that associations between dysfunctional cognitive schemes and negative mood are building up in episodes of depression (Risch, Stangier, Heidenreich, \& Hautzinger, 2012). Those associations are easier to reactivate once they have been established. The more they are reactivated, the easier a patient falls into the depressive mood. After a while the negative mood solely can lead to the occurrence of said dysfunctional cognitive schemes. In addition to that there is evidence for CBT that a lack of positive reinforcement leads is a main factor in depression (Hautzinger, 2008). The "Stiftung Deutsche Depressionshilfe" (German foundation for help for depression) (2016) describes on its homepage a five-level approach of CBT which primarily focusses on changing the negative patterns of thought. The first level is about defining the key elements of the patient's problem. What brings him or her into the therapy? The authors act on the assumption that it is in this first step where a working alliance between therapist and patient is built. The usage of the psychoanalytical term "Arbeitsbündnis" (Greenson, 1966) (working alliance) in the cognitive behavioural frame of mind points towards a general acceptance and acknowledgment of the "common factors" (Grencavage \& Norcross, 1990).

The second level targeted in CBT for depressed patients aims at the balance of the patient's activity. Over the time, a shift should be achieved towards less emotional wearing activities. The therapist helps the patient to discriminate different activities concerning the amount of distress they cause. The patient should increase the amount of relaxing activities or occupations linked to joy and well-being. The therapy works as a tool to help the patient with the evaluation of those activities. Through this, the patient develops a better feeling for how to improve his or her inner balance. The next step is to engage, with the backup of the therapist, in social interaction. Said engagement is rehearsed in a joint role play, where the therapist takes the place of possible others in difficult social situations. This is rather a re-engaging in the social structures the patient has been in before. A goal on this level is for the patient to distinguish deadlocked patterns of thought that slipped in over the episodes of depression. CBT aims to show their patients that those patterns of thought are a personal problem and cannot simply be attributed to a hostile society.

Second to last, the forth level again aims at some level of balancing. This time it's all about a balance between pleasant and unpleasant activities in the patient's daily life. In a way this acts as an implementation of the second level. While the second level focussed on the cognitive schemes responsible for the imbalance, on the fourth level the imbalance itself, in the patient's life is tackled. In the end this approach has a fifth step with the focus of retaining and stabilising the achieved results.

Language and Psychoanalysis, 2016, 5 (2), 27-45 
This method has its grounding in the theory that the patient is stuck in a so called "depressiven Spirale" (Berking \& Rief, 2012, S.43) (depression habit spiral) in which the negative mood of the patient and the lack of positive reinforcement from the outside world contribute to a vortex, sucking the patient in. The longer he stays in this condition, the deeper he gets and the more difficult it gets to escape it. The Behavioural therapist tries to interfere with this spiral in an attempt to decelerate or stop the force of the spiral. Hautzinger (2009, online-article) describes this as followed: "Goal and task of Cognitive Behavioural Therapy is to stop and reverse the depression habit spiral and to initiate a constructive, resolving development, respectively to gain control" (Author's own free translation from German to English).

In addition to the depression habit spiral there is also the factor of learned helplessness which has to be taken into account by the therapist. This central mechanism in the cognitive behavioural paradigm is defined by Craighead and Nemeroff (2004, p. 94): "In the field of clinical psychology, it has been suggested that ascribing negative events to something about the self that also is not subject to personal control produces a state of 'learned helplessness', which promotes and/or accompanies depression". The amount of perceived control over negative events contributes to the perception of those events. A person that experiences a lack of agency regarding the question "How do events in my life turn out?" learn that they can't help themselves in the face of a probably unpleasant situation. The models of treatment and description of depressive mechanisms presented so far are by no means to be seen as an exhaustive list for the way CBT deals with depression. They should rather act as sensitizing concepts along which we can enhance our interpretation of the analysed sequence.

\section{Bringing it all together}

In a first step we described in a fine-grained manner what kind of communicative manoeuvres the therapist and patient of this cognitive behavioural session engage in. This conversation analytic approach proves suitable for a very accurate look on the transcript. Subsequently we focused on the recipient signals of the therapist. At which points of the talk does he use one of those tokens? After what kind of utterances by the patient follow which kinds of recipient signals? To which reactions does the use of such a recipient signal lead? This step was done, influenced by conversation analytic, psychoanalytic and linguistic theories. Afterwards there was a short introduction to the disorder-specific theories and methods of Cognitive Behavioural Therapy regarding depression. This step can give answers to questions like: Which theoretical pre-conceptions help Cognitive Behavioural therapists when getting into contact with their patients? How do therapists perceive depression? Which ways of healing are prevalent in the school-specific canon? The synthesis of what was outlined in these different steps lies in the combination of the "data" (following Alexander (1982) and the "theōria" in the literal translation with what we know nowadays as theory of treatment.

The second level of the previously mentioned CBT-approach aims at the creation of a new balance between positive and negative activities in the patient's life. In advance to the analysed part of the therapy session the patient told that she does not have a head for private stuff at the moment. A therapist following the CBT-approach depicted by the "Stiftung Deutsche Depressionshilfe" (2016) would be expected to bring up a contrasting 
point of view. A point of view that helps the patient to shift in the direction of a more balanced situation where she might also have a head for her private stuff. The repetition of the date, first mentioned by the patient, and the subsequent proposal of a different perspective, from this date on, can be seen as an attempt to enter into negotiations with her on how she will try to balance her life in the future. But this doesn't happen. Instead of comparing notes with one another on how this date can be met or how other balancing forces can step into the life of the patient, an asymmetric communication is developing. The patient mainly follows the therapist in his perspective and is always answered with a confirming recipient signal (lines 14, 19 and 26) as long as she follows his proposed perception on how things change from the $2^{\text {nd }}$ of May on. If we take the depression habit spiral into account the quote by Hautzinger (2009) slightly changes: "Goal and task of [a Cognitive Behavioural therapist] is to stop and reverse the depression habit spiral and to initiate a constructive, resolving development, respectively to gain control" (Author's own free translation). The disclosure of new perspectives can have exactly this effect, but only if the patient can accept the proposal of the therapist as an option for herself. If this acceptance seizes to exist, the repetition of the therapists proposal remains a mere mimicking of what has been said by the person to help her.

In this transcript the therapist works also with two other techniques: Positive reinforcement and extinction of behaviour. Whenever the patient follows the perspective of the therapist, namely the change of pace after the $2^{\text {nd }}$ of May, she gets a similar reaction, a two-syllable-token "mhmh", picturing confirmation and agreement to her utterance. In the frame of classical conditioning this would increase the probability of the occurrence of a similar behaviour. Through this the therapist gets the patient to positively connote and further pursue his own perspective. If the patient restricts the fit of the therapists perspective or challenges the feasibility of the proposed idea another mechanism jumps in. The confirming two-syllable-token fails to appear, the patient does not get any further reinforcement in the moment of doubt. The paradigm of conditioning names this feature extinction The probability of occurrence is lowered when the desired reaction fails to appear. As an example line 21: All of a sudden, after she didn't get any reinforcing confirmation the patient shifts the direction of her thought.

The ways in which the knowledge of theoretical pre-conceptions change our point of view regarding our data resembles the idea of "Order at all points" proposed by Sacks. Each analysis of data comes with the question whether the examination produces, discovers or imposes theory. Surely, if one starts the search for one specific theory or even a set of theories in their transcripts or audio recordings, they will find it. By going back to the labelling of Psychotherapy as a form of communicative exchange, as a "talking cure" we find the necessary help to simplify this problem. A theoretical belief shows itself through the medium of talking. Therefore, by describing the communication of the participants first, we get a reliable basis for the further application of (meta-) theoretical concepts. Even though this first description seems to be rather atheoretical it is far from that. Linguistic as well as conversation analytic theories present themselves as toned glasses through which we look onto the data. There are always sensitizing concepts guiding our perception. As a result the continuum of scientific thought proposed by Alexander is rather a conceptual idea than applied in the (social) sciences. The two poles of the continuum cannot be reached due to the simple fact that theory and data are constantly interwoven. This poses no problem for science at all, as long as this 
interconnection is spelled out. To accept this interconnectivity means that one has to act under the presupposition of Theory at all points.

\section{Author's Biography}

The author is currently in the graduate program of the International Psychoanalytic University in Berlin and working in the CEMPP-Project (Conversation Analysis of Empathy in Psychotherapy Process Research) under the scientific lead of Prof. Michael Buchholz. Earlier publications dealt for example with Formulations in Psychotherapy. Together with the other contributors of this issue there have been two publications on 'Freudian Slips as a chance for Empathy' and on 'Architectures of Empathy'. 


\section{References}

Alexander, J. C. (1982). Theoretical logic in sociology, Vol. I: Positivism, presuppositions, and current controversies. Berkely and Los Angeles, California: University of California Press, Routledge.

Ameka, F. (1992a). Interjections: The universal yet neglected part of speech. Journal of Pragmatics, 18, 101-118.

Ameka, F. (1992b). The meaning of phatic and conative interjections. Journal of Pragmatics, 18, 245-271.

Aragno, A. (2008). The Language of empathy: an Analysis of its constitution, development, and role in psychoanalytic listening. Journal of the American Psychoanalytic Association, 56(3), 713-740.

Bakhtin, M. M. (2010). Speech genres and other late essays. Austin, TX: University of Texas Press.

Berking, M., \& Rief, W. (2012). Klinische Psychologie und Psychotherapie für Bachelor: Band 1 Grundlagen und Störungswissen. Berlin, Heidelberg, Germany: Springer.

Blumer, H. G. (1954). What is Wrong with Social Theory? American Sociological Review, 19 (1), 3-10.

Craighead, W. E., \& Nemeroff, C. B. (2004). The Concise Corsini Encyclopedia of Psychology and Behavioral Science. New Jersey, NY: John Wiley \& Sons.

Depressionshilfe, S. D. (2016, 09.08.2016, 00:03 Uhr). Verhaltenstherapie. Retrieved from http://www.deutsche-depressionshilfe.de/stiftung/psychotherapie.php

Dilling, H., Mombour, W., \& Schmidt, M. H. (2008). Internationale Klassifikation psychischer Störungen: ICD-10 Kapitel V $(F)$, Klinisch-diagnostische Leitlinien (6 ed.). Bern, Switzerland: Huber.

Ehlich, K. (1979). Formen und Funktionen von 'HM'. Eine phonologisch-pragmatische Analyse. In H. Weydt (Ed.), Die Partikeln der deutschen Sprache (pp. 503-517). Berlin: de Gruyter.

Freud, S. (1910a). Five lectures on psycho-analysis (Vol. 11). London, UK: Hogarth Press.

Freud, S. (1926e). The question of lay analysis (Vol. 20). London, UK: Hogarth Press.

Goffman, E. (1978). Response cries. Language, 787-815.

Greenson, R. (1966). Das Arbeitsbündnis und die Übertragungsneurose. Psyche, 2, 81103.

Grencavage, L. M., \& Norcross, J. C. (1990). Where are the commonalities among the therapeutic common factors? Professional psychology: Research and practice, 21, 372-378.

Harden, T. (1989). Na ja - ein vielseitiger Kommentar und seine portugiesischen Entsprechungen. In H. Weydt (Ed.), Sprechen mit Partikeln (pp. 141-149). Berlin: Walter de Gruyter.

Hautzinger, M. (2008). Depressionen. In M. Linden \& M. Hautzinger (Eds.), Verhaltenstherapiemanual. Heidelberg: Springer.

Hautzinger, M. (2009). Kognitive Verhaltenstherapie bei affektiven Störungen. Psychiatrie und Psychotherapie up2date, 3(01), 9-20.

Hoyer, J., Jacobi, F., \& Leibing, E. (2006). Gesprächsführung in der Verhaltenstherapie. In E. Leibing, W. Hiller, \& S. K. D. Sulz (Eds.), Verhaltenstherapie (Vol. 3, pp. 85102). München: CIP-Medien.

Leudar, I., \& Costall, A. (2009a). Against theory of mind. Houndmills, UK: Palgrave Macmillan.

Language and Psychoanalysis, 2016, 5 (2), 27-45

http://dx.doi.org/10.7565/landp.v5i2.1559 
Leudar, I., \& Costall, A. (2009b). On the historical antecedents of the theory of mind paradigm. In I. Leudar \& A. Costall (Eds.), Against theory of mind. Houndmills, UK: Palgrave Macmillan.

Norrick, N. R. (2009). Interjections as pragmatic markers. Journal of Pragmatics, 41(5), 866-891.

O'Keefe, A., \& Adolphs, S. (2008). Response tokens in British and Irish discourse: Corpus, context and variational pragmatics. In K. P. Schneider \& A. Barron (Eds.), Variational pragmatics: A focus on regional varieties in pluricentric languages (pp. 69-98). Amsterdam Philadelphia: John Benjamins Publishing.

Reddy, M. (1979). The conduit metaphor - a case of frame conflict in our language about language. In A. Ortony (Ed.), Metaphor and thought (pp. 164-201). Cambridge: Cambridge University Press.

Risch, A. K., Stangier, U., Heidenreich, T., \& Hautzinger, M. (2012). Kognitive Erhaltungstherapie bei rezidivierender Depression. Berlin: Springer.

Rodero, E. (2011). Intonation and emotion: influence of pitch levels and contour type on creating emotions. Journal of Voice, 25, e25-e34.

Sacks, H. (1995). Lectures on conversation (Vol. 1). Malden, USA: Blackwell Publishing.

Schachter, P., \& Shopen, T. (1985). Parts-of-speech systems. In T. Shopen (Ed.), Language Typology and Syntactic Description: Clause Structure (pp. 3-61). Cambridge: Cambridge University Press.

Schegloff, E. A. (1982). Discourse as an interactional achievement: Some uses of 'uh huh'and other things that come between sentences. In D. Tannen (Ed.), Analyzing discourse: Text and talk (pp. 71-93). Washington, D.C.: Georgetown University Press.

Streeck, U. (2006). Zur therapeutischen Beziehung in der Psychotherapie. In F. Leichsenring (Ed.), Psychoanalytische und tiefenpsychologisch fundierte Therapie (Vol. 2, pp. 33-48). München: CIP-Medien.

Tronick, E. (2005). Why is connection with others so critical? The formation of dyadic states of consciousness and the expansion of individuals' states of consciousness: coherence governed selection and the co-creation of meaning out of messy meaning making. In J. Nadel \& D. Muir (Eds.), Emotional development: Recent research advances (pp. 293-315). Oxford: Oxford University Press. 